\title{
Unexpected Pulmonary Embolism Late After Recovery from Mild COVID-19?
}

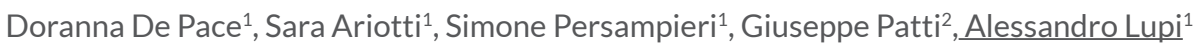 \\ ${ }^{1}$ Cardiology Division, Ospedale Unico Plurisede del VCO, Verbano-Cusio-Ossola, Italy \\ ${ }^{2}$ Clinica Cardiologica, AOU Maggiore della Carità, Università del Piemonte Orientale, Novara, Italy
}

\section{Doi: 10.12890/2021_002854- European Journal of Case Reports in Internal Medicine - ๑ EFIM 2021}

Received: 29/08/2021

Accepted: 22/11/2021

Published: 21/12/2021

\begin{abstract}
How to cite this article: De Pace D, Ariotti S, Persamieri S, Patti G, Lupi A. Unexpected pulmonary embolism late after recovery from mild COVID-19.
\end{abstract} EJCRIM 2021;8: doi:10.12890/2021_002854.

Conflicts of Interests: The authors declare there are no competing interests.

This article is licensed under a Commons Attribution Non-Commercial 4.0 License

\section{ABSTRACT}

SARS-CoV-2 infection is associated with an increased risk of venous thromboembolism (VTE), which is common during active illness but unusual in milder cases and after healing. We describe a case of bilateral acute pulmonary embolism occurring 3 months after recovery from a paucisymptomatic SARS-CoV-2 infection. The only VTE risk factor demonstrable was a history of previous SARS-CoV-2 infection, with laboratory signs of residual low-grade inflammation. Clinicians should be aware of VTE as a potential cause of sudden dyspnoea after COVID-19 resolution, especially in the presence of persistent systemic inflammation.

\section{LEARNING POINTS}

- Venous thromboembolism may occur after COVID-19, even in milder SARS-CoV-2 infections and late after coronavirus clearance.

- Laboratory signs of systemic inflammation are clues for suspecting venous thromboembolism as a cause of sudden dyspnoea in patients with low risk scores for pulmonary embolism but with previous COVID-19 infection.

\section{KEYWORDS}

SARS-CoV-2, COVID-19, thrombosis, inflammation, pulmonary embolism, direct oral anticoagulants

\section{INTRODUCTION}

COVID-19 clinical pulmonary manifestations range from mild interstitial pneumonitis to acute respiratory distress syndrome ${ }^{[1]}$, but SARSCoV-2 binding to the transmembrane ACE2 receptor can also target the cardiovascular system ${ }^{[2]}$. Direct viral infection of endothelial cells and immune-mediated endothelial damage ${ }^{[3]}$ can result in a cytokine release syndrome and widespread endothelial dysfunction and apoptosis, predisposing to microvascular dysfunction, vasoconstriction, inflammation and thrombophilia ${ }^{[4]}$.

Thromboembolic complications are common in patients with severe COVID-19 ${ }^{[2]}$ with a high risk of venous thromboembolism (VTE), particularly in severe COVID-19 patients bedridden in intensive care units ${ }^{[5]}$. Coagulation abnormalities described in association with SARS-CoV-2 infection constitute the 'COVID-19-associated coagulopathy' ${ }^{[6]}$, which is the pathophysiological substrate of the increased VTE risk described in COVID-19 patients ${ }^{[7]}$.

Most of the VTE complicating COVID-19 reported so far have occurred in critically ill patients during hospital stay ${ }^{[8-10]}$ but have occasionally been observed in mild SARS-CoV-2 infections and within a few days after discharge ${ }^{[11]}$. Finally, very few episodes of VTE were observed later after COVID-19, generally in the first 4 weeks after SARS-CoV-2 clearance ${ }^{[11]}$.

We report a case of multivessel pulmonary embolism (PE) occurring without major VTE risk factors 3 months after a mild case of SARSCoV-2 infection. 


\section{CASE DESCRIPTION}

In July 2020, a 72-year-old male patient accessed our institution for an outpatient visit due to dyspnoea on minimal efforts. Three months before, the patient had suffered mild upper respiratory tract signs of viral infection. On that occasion, an oropharyngeal screening swab (molecular testing) was positive for SARS-CoV-2 infection, and the patient was quarantined at home until SARS-CoV-2 clearance, 3 weeks following the first positive test.

Current physical examination showed a blood pressure of $120 / 80 \mathrm{mmHg}$, a heart rate of $95 / \mathrm{min}$, a respiratory rate of $21 / \mathrm{min}$, and a pulseoximetric $\mathrm{O} 2$ saturation of $93 \%$. ECG showed sinus rhythm with right bundle branch block. Arterial blood gas analysis showed mild hypoxia and hypocapnia with slight desaturation, D-dimer and NT-proBNP were frankly above the normal range, and cTnl and CRP were slightly elevated (Table 1).

\begin{tabular}{|c|c|c|}
\hline & Baseline & Reference value \\
\hline \multicolumn{3}{|l|}{ Blood gas analysis (FiO2 21\%) } \\
\hline $\mathrm{pO} 2(\mathrm{mmHg})$ & 78 & $(80-100)$ \\
\hline$p \mathrm{CO} 2(\mathrm{mmHg})$ & 28 & $(35-45)$ \\
\hline$p H$ & 7.44 & (7.35-7.45) \\
\hline O2 saturation (\%) & 92 & $(>95)$ \\
\hline \multicolumn{3}{|l|}{ Blood cell count } \\
\hline$R B C(\times 103 / \mathrm{mm} 3)$ & 4.42 & $(4.00-5.00)$ \\
\hline $\mathrm{Hb}(\mathrm{g} / \mathrm{dl})$ & 14.8 & $(12.0-15.0)$ \\
\hline WBC $(\times 103 / \mathrm{mm} 3)$ & 6.31 & $(4.80-10.80)$ \\
\hline Neutrophils $(\times 103 / \mathrm{mm} 3)$ & 3.45 & $(1.90-8.00)$ \\
\hline Lymphocytes (x103/mm3) & 1.97 & $(0.90-5.20)$ \\
\hline Platelets (×103/mm3) & 133 & $(130-400)$ \\
\hline \multicolumn{3}{|l|}{ Clinical chemistry } \\
\hline Fibrinogen (mg/dl) & 408 & $(196-441)$ \\
\hline$D$-dimer (mg/dl) & 1250 & $(0-232)$ \\
\hline$c \operatorname{Tnl}(\mathrm{ng} / \mathrm{dl})$ & 0.44 & $(0.000-0.0014)$ \\
\hline C-reactive protein (mg/dl) & 1.89 & $(0.00-0.50)$ \\
\hline Partial thromboplastin time (sec) & 38 & $(30-40)$ \\
\hline Prothrombin time (sec) & 11.8 & $(9.5-13.8)$ \\
\hline \multicolumn{3}{|l|}{ Occult cancer markers } \\
\hline CEA & 2.1 & $(0.0-5.0)$ \\
\hline $\mathrm{Ca} 19-9$ & 6.8 & $(0.0-37.0)$ \\
\hline Alfa-fetoprotein & 3.8 & $(<7.0)$ \\
\hline PSA & 0.433 & $(0.000-2.500)$ \\
\hline Cyfra 21-1 & 2.2 & $(<3.3)$ \\
\hline \multicolumn{3}{|l|}{ Thrombophilia markers } \\
\hline Antithrombin III & 102 & $(80-120)$ \\
\hline Protein S & 99 & (75-130) \\
\hline Protein C & 108 & $(70-140)$ \\
\hline Lupus anticoagulant & Absent & Absent \\
\hline Anticardiolipin antibodies & 0 & $(0-20)$ \\
\hline Anti $\beta 2$ GPI antibodies & 0 & $(0-20)$ \\
\hline Factor V Leiden & Absent & Absent \\
\hline Prothrombin variant G20210A & 0.97 & $(0.70-1.35)$ \\
\hline \multicolumn{3}{|l|}{ Diagnostic scores } \\
\hline Revised GENEVA score & 1 & (0-3: low PE probability) \\
\hline Simplified revised GENEVA score & 1 & (0-2: PE unlikely) \\
\hline
\end{tabular}

Table 1. Laboratory data at admission and during the hospital stay CEA, carcinoembryonic antigen; cTnl, cardiac troponin I; FiO2, fraction of inspired $\mathrm{O} 2 ; \mathrm{Hb}$, haemoglobin; $\mathrm{PSA}$, prostate-specific antigen; $\mathrm{RBC}$, red blood cells; WBC, white blood cells. 
Echocardiography disclosed a slightly dilated and hypokinetic right ventricle with a mildly increased trans-tricuspid gradient (Fig. 1). Finally, chest computed tomography with pulmonary angiography (CTPA) demonstrated multiple bilateral segmental and subsegmental PE without signs of interstitial lung disease (Fig. 2A,C).
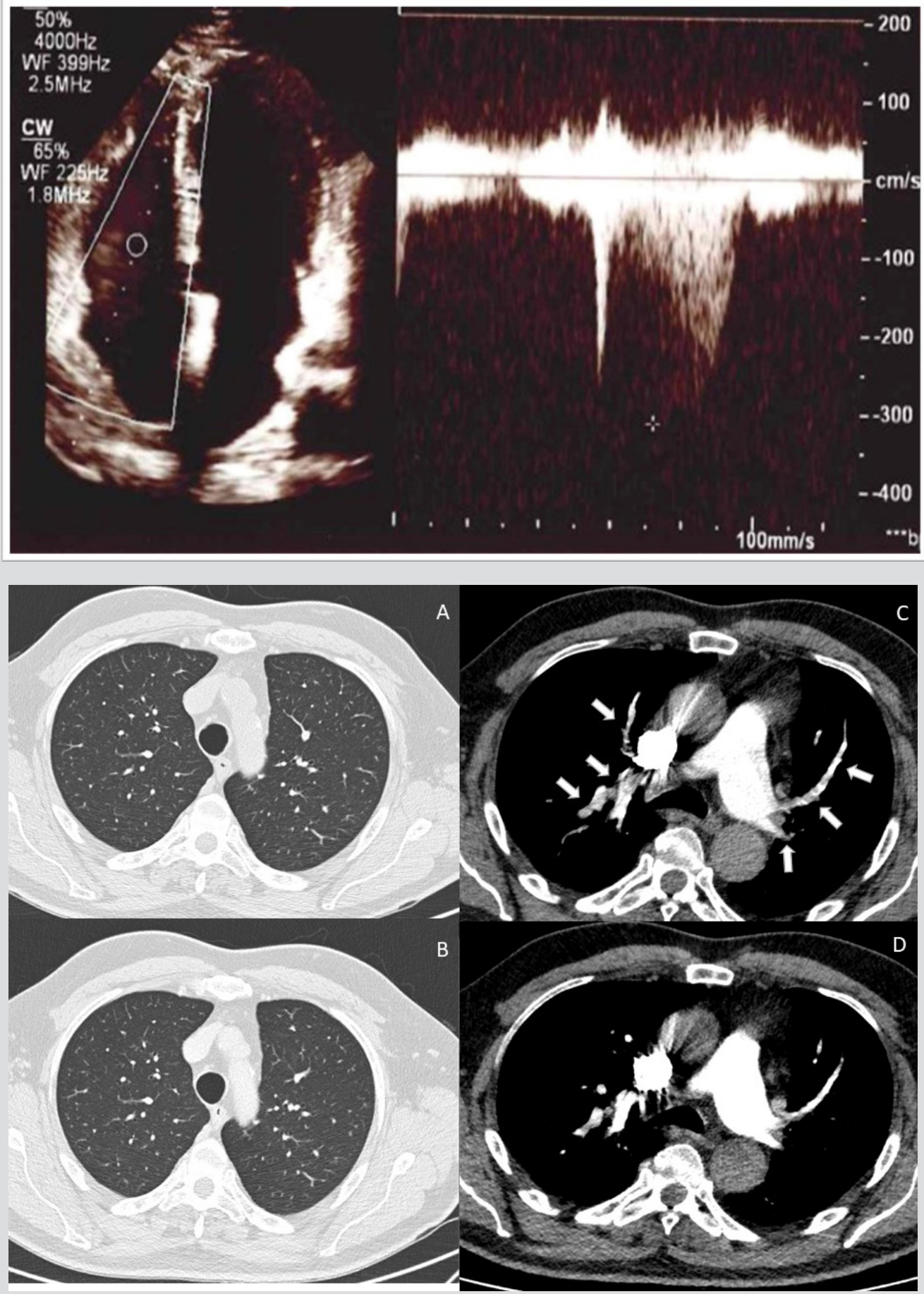

Figure 1 Echocardiogram showing a left ventricle with normal size and normal global and segmental systolic function and a mildly dilated right ventricle with indirect signs of mild pulmonary hypertension (systolic pulmonary arterial pressure estimates of $30+10=40 \mathrm{mmHg}$ )

Figure 2. Computed tomographic study of the chest performed at the first clinical presentation and after 3-month follow-up, showing: (A) CT scan of the pulmonary parenchyma, showing absence of interstitial involvement at baseline and (B) at 3-month follow-up; (C) CT pulmonary angiography showing multiple bilateral segmental and subsegmental pulmonary emboli; (D) followup CT pulmonary angiography after 3 months of anticoagulant treatment, showing resolved pulmonary emboli

After hospital admission, two consecutive SARS-CoV-2 molecular swabs resulted negative. The blood total IgG ECLIA anti-S test level was $92 \mathrm{U} / \mathrm{ml}$, confirming previous SARS-CoV-2 infection. 
Doppler ultrasound and CT scanning failed to reveal PE sources. Oncological markers and a total-body CT screening for occult cancer were unremarkable. Normal levels of antithrombin III, protein S, protein C and negativity for lupus anticoagulant, anticardiolipin and anti $\beta 2$ GPI antibodies, factor V Leiden and prothrombin variant G20210A excluded thrombophilic states commonly associated with VTE.

The patient received apixaban (10 mg twice daily for 7 days, followed by $5 \mathrm{mg}$ twice daily after discharge) with rapid improvement of shortness of breath. At 1 month follow-up, the patient was asymptomatic, the right ventricle and trans-tricuspid gradient had turned normal, and CTPA demonstrated complete PE resolution (Fig. 2B,D). Apixaban was stopped 6 months after discharge. At 1 year follow-up, the patient was asymptomatic and free from any laboratory or instrumental evidence of VTE recurrence or cancer development.

\section{DISCUSSION}

Thrombophilia and coagulopathy are essential mechanisms of COVID-19 ${ }^{[7]}$. Pulmonary microvascular thrombosis is probably the epiphenomenon of extensive pulmonary damage involving alveoli and the pulmonary microvessels and probably generates 'in loco' [12]. However, PE involving larger pulmonary arteries are common in patients with active COVID-19 ${ }^{[9,10]}$ and is presumably due to a combination

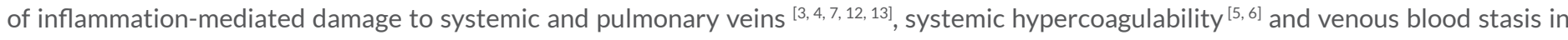
bedridden patients ${ }^{[5]}$. Some theories indicated cytokine up-regulation as a possible contributor ${ }^{[3,13]}$. Others believe that hepatic dysfunction may play a role in COVID-19 coagulopathy [5], with clinical pictures resembling disseminated intravascular coagulation [5].

Generally, the thrombotic complications of COVID-19 occur in strict temporal association with SARS-CoV-2 infection, often coinciding with the most severe and symptomatic phases of the disease ${ }^{[10,14]}$. In our case, unexpected PE occurred 3 months after a mild SARSCoV-2 infection. The hypothesis that it was a late COVID-19 sequela is intriguing but hard to demonstrate. Our lab work showed a slight increase in PCR levels, indicating persisting inflammation resulting from late activation of autoimmunity, a recently described late COVID-19 complication. Assini et al. reported a case of myasthenia gravis 8 weeks after recovery from COVID-19 [15]. Moreover, Nicol et al. diagnosed acute autoimmune myocarditis 4 weeks after SARS-CoV-2 infection ${ }^{[16]}$. Of note, in this case, viral RNA was not demonstrable within myocardium biopsy specimens. Taherifard et al. performed a systematic review of 94 patients with COVID-19 who developed a haematological autoimmune disorder at various stages of infection ${ }^{[17]}$. Finally, Vechi et al. published a case series of five patients with mild COVID-19 who developed VTE between the third and the fourth weeks after the onset of symptoms ${ }^{[11]}$.

The mechanisms through which viral infection might induce persistent inflammation and eventually trigger autoimmunity have not been fully clarified. Increased release of type I interferons and other pro-inflammatory cytokines, T cell activation, molecular mimicry and epitope spreading may be involved ${ }^{[5]}$.

High D-dimer levels support VTE diagnosis and add crucial prognostic information ${ }^{[18]}$. D-dimer was indeed elevated in our patient when VTE symptoms developed (Table 1), but unfortunately, it had not been assessed in the convalescent phase following SARS-CoV-2 infection. However, it is reasonable that the persistence of inflammatory and thrombosis markers in patients with apparently resolved COVID-19 could suggest an increased risk of VTE and the need for closer clinical monitoring.

In the present case, oral anticoagulation with a direct oral anticoagulant (DOAC) led to complete restoration of the pulmonary artery bed patency and normalization of right heart dimensions and function. The recommended PE treatment in patients with SARS-CoV-2 infection is low-molecular-weight heparin ${ }^{[5]}$, with concerns about the optimal dose ${ }^{[19]}$. However, PE occurring in patients convalescing from COVID-19 showed a favourable response to standard dose DOACs ${ }^{[11]}$. Thus when we excluded the recurrence of SARS-CoV-2 infection, we felt confident treating the disease according to current PE guidelines, regardless of any possible origin of the thrombosis. Echocardiographic and CTPA signs of PE promptly disappeared after apixaban treatment.

\section{CONCLUSIONS}

We have described a VTE case occurring without predisposing risk factors 3 months after SARS-CoV-2 infection. Unlike more common COVID-19-associated VTE presentations, the clinical COVID-19 presentation was mild, and VTE occurred late after viral clearance. Clinicians should be aware that a low VTE risk does not exclude PE as a cause of sudden dyspnoea in patients with previous COVID-19, even late after recovery. 


\section{REFERENCES}

1. Huang C, Wang Y, Li X, Ren L, Zhao J, Hu Y, et al. Clinical features of patients infected with 2019 novel coronavirus in Wuhan, China. Lancet 2020;395(10223):497-506.

2. Guzik TJ, Mohiddin SA, Dimarco A, Patel V, Savvatis K, Marelli-Berg FM, et al. COVID-19 and the cardiovascular system: implications for risk assessment, diagnosis, and treatment options. Cardiovasc Res 2020;116(10):1666-1687.

3. Varga Z, Flammer AJ, Steiger P, Haberecker M, Andermatt R, Zinkernagel AS, et al. Endothelial cell infection and endotheliitis in COVID-19. Lancet 2020;395(10234):14171418.

4. Teuwen LA, Geldhof V, Pasut A, Carmeliet P. COVID-19: the vasculature unleashed. Nat Rev Immunol 2020;20(7):389-391.

5. Bikdeli B, Madhavan MV, Jimenez D, Chuich T, Dreyfus I, Driggin E, et al. COVID-19 and thrombotic or thromboembolic disease: implications for prevention, antithrombotic therapy, and follow-up: JACC state-of-the-art review. J Am Coll Cardiol 2020;75(23):2950-2973.

6. Connors JM, Levy JH. COVID-19 and its implications for thrombosis and anticoagulation. Blood 2020;135(23):2033-2040.

7. Connors JM, Levy JH. Thromboinflammation and the hypercoagulability of COVID-19. J Thromb Haemost 2020;18(7):1559-1561.

8. Poissy J, Goutay J, Caplan M, Parmentier E, Duburcq T, Lassalle F, et al. Pulmonary embolism in patients with COVID-19: awareness of an increased prevalence. Circulation 2020;142(2):184-186.

9. Klok FA, Kruip M, van der Meer NJM, Arbous MS, Gommers D, Kant KM, et al. Confirmation of the high cumulative incidence of thrombotic complications in critically ill ICU patients with COVID-19: an updated analysis. Thromb Res 2020;191:148-150.

10. Dutch COVID \& Thrombosis Coalition, Kaptein FHJ, Stals MAM, Grootenboers M, Braken SJE, Burggraaf JLI, van Bussel BCT, et al. Incidence of thrombotic complications and overall survival in hospitalized patients with COVID-19 in the second and first wave. Thromb Res 2021;199:143-148.

11. Vechi HT, Maia LR, Alves MDM. Late acute pulmonary embolism after mild coronavirus disease 2019 (COVID-19): a case series. Rev Inst Med Trop Sao Paulo 2020;62:e63.

12. Bryce C, Grimes Z, Pujadas E, Ahuja S, Beasley MB, Albrecht R, et al. Pathophysiology of SARS-CoV-2: the Mount Sinai COVID-19 autopsy experience. Mod Pathol 2021;34(8):1456-1467.

13. Mehta P, McAuley DF, Brown M, Sanchez E, Tattersall RS, Manson JJ, et al. COVID-19: consider cytokine storm syndromes and immunosuppression. Lancet 2020;395(10229):1033-1034.

14. Klok FA, Kruip M, van der Meer NJM, Arbous MS, Gommers D, Kant KM, et al. Incidence of thrombotic complications in critically ill ICU patients with COVID-19. Thromb Res 2020;191:145-147.

15. Assini A, Gandoglia I, Damato V, Rikani K, Evoli A, Del Sette M. Myasthenia gravis associated with anti-MuSK antibodies developed after SARS-CoV-2 infection. Eur J Neurol 2021;28(10):3537-3539.

16. Nicol M, Cacoub L, Baudet M, Nahmani Y, Cacoub P, Cohen-Solal A, et al. Delayed acute myocarditis and COVID-19-related multisystem inflammatory syndrome. ESC Heart Fail 2020;7(6):4371-4376.

17. Taherifard E, Taherifard E, Movahed H, Mousavi MR. Hematologic autoimmune disorders in the course of COVID-19: a systematic review of reported cases. Hematology 2021:26(1):225-239.

18. Nickel CH, Kellett J, Cooksley T, Lyngholm LE, Chang S, Imfeld S, et al. The diagnoses and outcomes of emergency patients with an elevated D-dimer over the next 90 days. Am J Med 2021;134(2):260-266.e2.

19. Mennuni MG, Renda G, Grisafi L, Rognoni A, Colombo C, Lio V, et al. Clinical outcome with different doses of low-molecular-weight heparin in patients hospitalized for COVID-19. J Thromb Thrombolysis 2021;52(3):782-790. 